\title{
Estimation of Related Substances in Tigecycline by rp-hplc Method
}

\section{BAVIREDDI MOHAN ${ }^{1}$, R. S. K. SHARMA ${ }^{1}$, S. V. MURALI MOHAN RAO ${ }^{1 *}$ and N.V.S. VENU GOPAL ${ }^{1 *}$}

\author{
1Department of Chemistry, GITAMUniversity, Gandhi Nag Rust «nda, \\ Visakhapatnam-530045, Andhra Prader diá. \\ *ICorresponding author E-mail: bavirddim @e ile com \\ http://dx.doi.org/10.13005/ojc, 2558 \\ (Received: June 14, 2017; A spteo July 18, 2017)
}$$
\text { A ST }
$$

Estimation of related substanc

y usir

-performance liquid chromatographic method was developed and validated $f_{c}$ th $\mathrm{a}_{\mathrm{a}}$ mination of Tigecycline in the present work. Reversedphase chromatography was per ed on. 'aters 2489 UV 2695 pump, Waters 2998 PDA 2695 pump Software Empower ${ }^{2}$ photodic array detector using Zorbax Eclipse plus C18 $(100 \mathrm{~mm} \times$ $4.6 \mathrm{~mm}, 1.8 \mu \mathrm{m}$ particle siz nn . eluent-A: $\mathrm{pH} 6.50$ buffer: acetonitrile: DMSO $(90: 5: 5 \% \mathrm{v} /$ $\mathrm{v} / \mathrm{v})$ and eluent-B: $\mathrm{pH} 6.5$ uf if cetonitrile: DMSO $(71: 24: 5 \% \mathrm{v} / \mathrm{v} / \mathrm{v})$ as mobile phase at a flow rate of $1.0 \mathrm{~mL} / \mathrm{m}$ ' $U \backslash$ ect 1 at $270 \mathrm{~nm}$. Linearity was observed in the concentration range of Tigecyclin $.0 Q-13 \%(1.000)$, the concentration range of di-MA-TIG impurity $0.04-$ $0.23 \%(R 2=00)$ nantration range of CMI 0.05-0.23\% $(R 2=0.999)$. The limit of quantitation (LOQ) and lim. detection (LOD) were found to be di-MA-TIG impurity 0.0001 and $0.0004 \mathrm{mg} /$ $\mathrm{mL}, \mathrm{CMI}$ impurity 001 and $0.0004 \mu \mathrm{g} / \mathrm{mL}$, Tigecycline 0.0001 and $0.0005 \mathrm{mg} / \mathrm{mL}$ respectively. The method was validat, as per ICH guidelines. The \%RSD precision was found to be less than 1.0 $\%$. The percentage recovery was in good agreement with the labeled amount in the pharmaceutical formulations and the method is simple, specific, precise and accurate for the determination of Tigecycline in pharmaceutical formulations.
\end{abstract}

Keywords: Tigecycline, Estimation of related substances, validation and reverse phase-liquid chromatography,

\section{INTRODUCTION}

Tigecycline [TIG] is $(4 \mathrm{~S}, 4 \mathrm{aS}, 5 \mathrm{aR}, 12 \mathrm{aS})$ 9-[2-(tert-butylamino)acetamido]-4,7-bis (dimethylamino)-1,4,4a, 5, 5a, 6, 11, 12 a-octahydro $3,10,12,12$ atetrahydroxy-1,11-dioxo-2naphthacenecarboxamide. Tigecycline is a new glycylcycline with an expanded broad spectrum antibiotic, including inhibition of Gram positive, anaerobic and antibiotic resistant organisms. Studies have demonstrated that Tigecycline is superior to the treatment of complicated skin infections as well as complicated intra-abdominal infections. Tigecycline is only available as an intravenous injection ${ }^{1}$.

There are only limited reports regarding determination of Tigecycline in pharmaceutical 
dosage forms and biological fluids such as spectrophotometric ${ }^{2-4}$ and HPLC methods ${ }^{5-7}$ to determine Tigecycline in pharmaceutical dosage forms. The assay of Tigecycline in the human bone is also reported by LC-MS method ${ }^{8}$.

Tigecycline is not official in any pharmacopoeia and there is no monograph containing methods to characterize or quantify Tigecycline. Such methods could offer official parameters to guarantee the validity of the assay. Hence, there is a need for simple, rapid and reproducible method for the routine analysis of Tigecycline in pharmaceutical dosage forms. There is not even a single method estimation of impurities in TIG by using RP-liquid chromatographic method in pharmaceutical dosage forms. In the present work a simple estimation of impurities in TIG reverse phase liquid chromatographic method has been developed for the determination of TIG and validated as per $\mathrm{ICH}$ guidelines ${ }^{9-11}$.

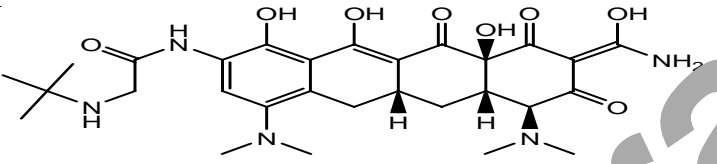

Fig.1.1 Chemical Structure of Tigec cline ()).

Related substance structures:

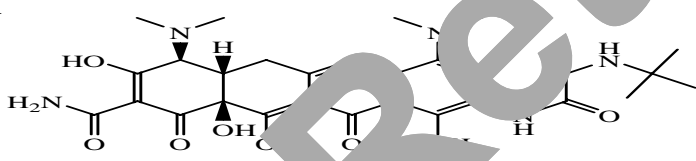

Fig. 1.2 Chemical ucture of TIG-6-ene.

(i) TIG-6-ene $=(4 \mathrm{~S}, 4 \mathrm{aS}$, oaR, 12aS)-9-(2-(tertbutylamino)acetamido)-4,7-bis(dimethylamino)1,4,4a,5,11,12a-hexahydro-3,10,12,12ate trah y droxy-1,11-dioxo-2naphthacenecarboxamide.

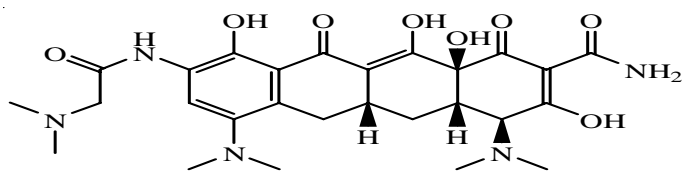

Fig. 1.3 Chemical Structure of di-MA-TIG.

(ii) di-MA-TIG $=(4 \mathrm{~S}, 4 \mathrm{aS}, 5 \mathrm{aR}, 12 \mathrm{aS})-9-(2-$ (dimethylamino) acetamido-4, 7 bis(dimethylamino)-1,4,4a,5,5a,6,11,12aoctahydro-3,10,12,12a-tetrahydroxy-1,11dioxo-2-naphthacenecarboxamide.

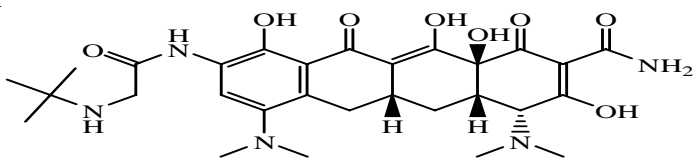

Fig. 1.4 Chemical Structure of epi-TIG.

(iii) epi-TIG $=(4 \mathrm{R}, 4 \mathrm{aS}, 5 \mathrm{aR}, 12 \mathrm{aS})$-9-(2-(tertbutylamino)acetamido)-4,7-bis(dimethylamino),4,4a,5,5a,6,11,12a-octahydro-3,10,12,12at e trah y d rox - 1, 11-dioxo-2aphthacenecarboxamide.

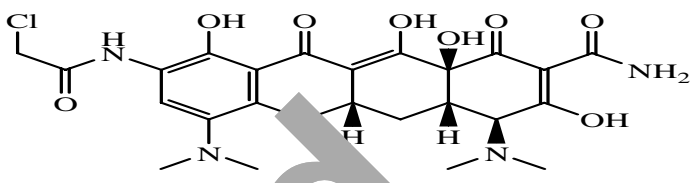

Fig..1.5 Che ical S ture of CMI.

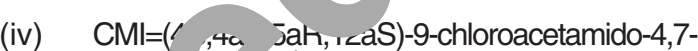
'his(din b am ) )-1,4,4a,5,5a,6,11,12aoctahydro0,1 . - tetrahydroxy-1,11-dioxo-2nap. necarboxamide.

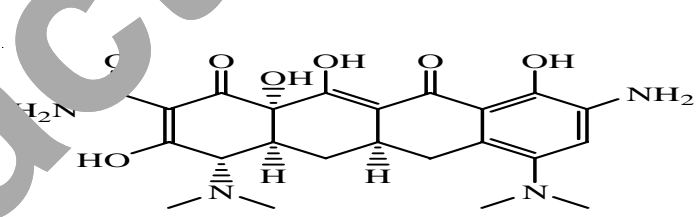

Fig. 1.6 Chemical Structure of AMC.

(v) $\quad \mathbf{A M C}=(4 \mathrm{~S}, 4 \mathrm{aS}, 5 \mathrm{aR}, 12 \mathrm{aS})-9$-amino-4,7bis(dimethylamino)-3,10,12,12a-tetrahydroxy-1,11dioxo-1,4,4a,5,5a,6,11,12a-octahydrotetracene-2carboxamide.

\section{EXPERIMANTAL}

\section{Reagents and Chemicals}

Ammonium acetate, Acetonitrile (HPLC grade), Dimethyl sulfoxide (DMSO) and Ethylenediamine tetra acetic acid disodium dihydrate (EDTA $\mathrm{Na}_{2} \cdot 2 \mathrm{H}_{2} \mathrm{O}$ ) were obtained from Merck (India). All chemicals were of an analytical grade and used as received.

\section{Preparation of $\mathrm{pH} 6.50$ buffer}

$1.54 \mathrm{~g}$ of Ammonium acetate, $3.7224 \mathrm{~g}$ of Ethylenediaminetetraacetic acid, disodium dihydrate in $1000 \mathrm{~mL}$ HPLC grade water sonicated to dissolve then adjusted $\mathrm{pH} 6.50$ with $25 \%$ aqueous ammonia solution. Filtered through 0.45 umembrane filter paper and degassed. 


\section{Preparation of buffer}

$1.54 \mathrm{~g}$ of Ammonium acetate, $3.72 \mathrm{~g}$ of Ethylenediaminetetraacetic acid, disodium dihydrate and $0.66 \mathrm{gms}$ of Sodium sulfitein $1000 \mathrm{ml}$ HPLC grade water sonicated to dissolve then adjusted top $\mathrm{H} 6.50$ with $25 \%$ aqueous ammonia solution. Filtered through $0.45 \mu$ membrane filter paper and degassed. Transferred above buffer, acetonitrile and of dimethyl sulfoxide in the ratio of

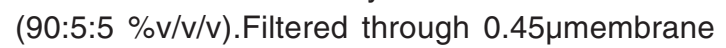
filter paper and degassed.

\section{Chromatographic conditions}

Chromatographic separation was achieved by using a Waters 2489 UV 2695 pump, Waters 2998 PDA 2695 pump Software Empower ${ }^{2}$ photodiode array detector using Zorbax Eclipse plus C18 (100 mm $\times 4.6 \mathrm{~mm}, 1.8 \mu \mathrm{m}$ particle size) column with eluent-A: pH 6.50 buffer: acetonitrile:DMSO (90:5:5\%v/v/v) and eluent-B: $\mathrm{pH}$ 6.50 buffer: acetonitrile: DMSO $(71: 24: 5 \% \mathrm{v} / \mathrm{v} / \mathrm{v})$ as mobile phase at a flow rate of $1.0 \mathrm{~mL} / \mathrm{min}$. with UV detection at $270 \mathrm{~nm}$. Column maintained at temperature $30 \stackrel{\circ}{\circ}$, sample temperature $2-5 \circ \mathrm{C}$. $\mathrm{Tr}$ overall run time was $26 \mathrm{~min}$. and the flow rate $\mathrm{n}$; $1.0 \mathrm{~mL} / \mathrm{min}$. $10 \mu \mathrm{l}$ of sample was injected in the HPLC system. Retention times of in uritic vere $13.50 \mathrm{~min}$ for di-MA-TIG impurity, 16. ' $n$ for $1 /$ and $14.35 \mathrm{~min}$ for Tigecycline.

\section{Method validation \\ System suitability}

The systen. it performed by analyzing the referer. solution three times. Calculate \% RSD for rep. te injections of each component from reference solution.Preparations of Tigecycline, di-MA-TIG and CMI standard at concentrations: $28.500 \times 10^{-3} \mathrm{mg} / \mathrm{ml}(0.7 \%)$, $5.0516 \times 0^{-3} \mathrm{mg} / \mathrm{ml} 0.15 \%$ and $5.0516 \times 10^{-3} \mathrm{mg} / \mathrm{ml}$ $0.15 \%$ of the nominal concentration of sample

Table 1.1: Summary of system suitability from reference solution.

\begin{tabular}{lccc}
\hline Injection No & Tigecycline & di-MA-TIG & CMI \\
\hline 1 & 484950 & 78622 & 110620 \\
2 & 486317 & 78114 & 109323 \\
3 & 485113 & 78903 & 109471 \\
Mean & 485460 & 78546 & 109805 \\
\%RSD & 0.2 & 0.5 & 0.6 \\
\hline
\end{tabular}

required by the method were analyzed in triplicate for each solution according to the method. The details of summary of system suitability from reference solution were incorporated in the Table 1.1.

\section{Specificity}

Solutions of TIG-6-ene impurity, di-MA-TIG impurity, epi-TIG impurity, CMI impurity, AMC impurity and Tigecycline each were prepared and analysed individually. A spiked solution of each potential impurity to the Tigecycline drug substance was preapred and analyzed. Performed the analysis using PDA detector and the peak purity was determined.Th study showed that all the known impurities of cycline are adequately

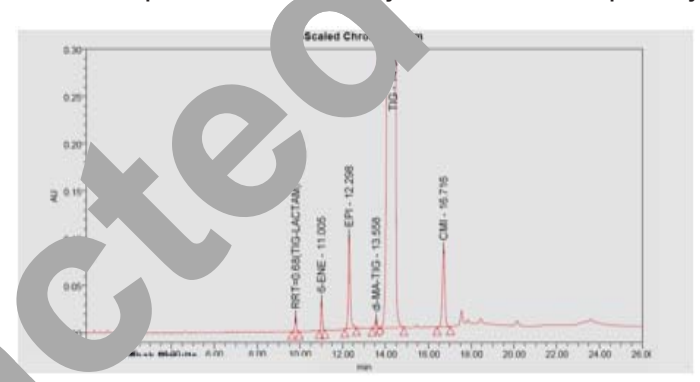

Tig 1.7. Specificity chromatogram of Spiked Solution.

Table 1.2: Summary of retention time, and relative retention time for known impurities

\begin{tabular}{lcc}
\hline $\begin{array}{l}\text { Peak } \\
\text { Name }\end{array}$ & $\begin{array}{c}\text { Retention } \\
\text { Time }\end{array}$ & $\begin{array}{c}\text { Relative retention } \\
\text { time(RRT) }\end{array}$ \\
\hline TIG-Lactam & 9.804 & 0.68 \\
TIG-6-ene & 11.005 & 0.77 \\
Epi-TIG & 12.298 & 0.85 \\
di-MA-TIG & 13.558 & 0.94 \\
Tigecycline & 14.366 & 1.00 \\
CMI & 16.716 & 1.16 \\
\hline
\end{tabular}

resolved and the details of retention time and relative retention time for known impurities were presented in the Table 1.2. Therefore the method is selective for the determination of related substances in Tigecycline.

\section{Limit of Detection}

A solution containing $0.8152 \times 10^{-3} \mathrm{mg} / \mathrm{ml}$ of Tigecycline standard $(0.02 \%$ of the nominal concentration of a sample), $0.8152 \times 10^{-3} \mathrm{mg} / \mathrm{ml}$ of di-MA-TIG standard $(0.02 \%$ of the nominal 
concentration of a sample) and $0.8368 \times 10^{-3} \mathrm{mg} /$ $\mathrm{ml}$ of $\mathrm{CMI}$ standard $(0.02 \%$ of the nominal concentration of a sample), was injected three times. The worst found signal to noise ratio for each

\section{Linearty and Range}

The linearity is determined by injecting the solutions in duplicate containing known impurities and Tigecycline ranging from 0.05 to $1.13 \%$ and

Table: 1.3 Limit of detection (LOD) for Tigecycline and impurities.

\begin{tabular}{lcccccc}
\hline S.No & Area & $\begin{array}{c}\text { Tigecycline } \\
\text { conc.mg/ml }\end{array}$ & Area & $\begin{array}{c}\text { di-MA-TIG } \\
\text { conc.mg/ml }\end{array}$ & Area & $\begin{array}{c}\text { CMI } \\
\text { conc.mg/ml }\end{array}$ \\
\hline 1 & 10448 & 0.00015664 & 7908 & 0.000126917 & 10977 & 0.00014494 \\
2 & 10629 & 0.00015930 & 7967 & 0.000127856 & 10965 & 0.00014479 \\
3 & 10436 & 0.00015647 & 8045 & 0.000129114 & 11018 & 0.00014542 \\
Mean & 10504 & & 7973 & & 10986 & \\
\%RSD & 1.0 & & 0.9 & & 0 & \\
\hline
\end{tabular}

peak was greater than 3 in each injection. All the peaks were detected in all the three injections. Results of LOD for Tigecycline and impurities were shown in Table 1.3. The limit of detection values obtained for each impurity and Tigecycline are within the acceptance criteria.

impurities ranging om $5 \%$ to $0.22 \%$ of the specified limit. Regr sion r.alysis was performed and the corre cou ent and residual sum of squares wer dr or ined. The response factor for each urit, it' respect to Tigecycline was determin hinearity range as the range for d' ermining ....e impurities were reported. Results 0 ainec ire incorporated in Table1.5- Table 1.7

Table: 1.4 Limit of Quantita riy_ycline and impurities.

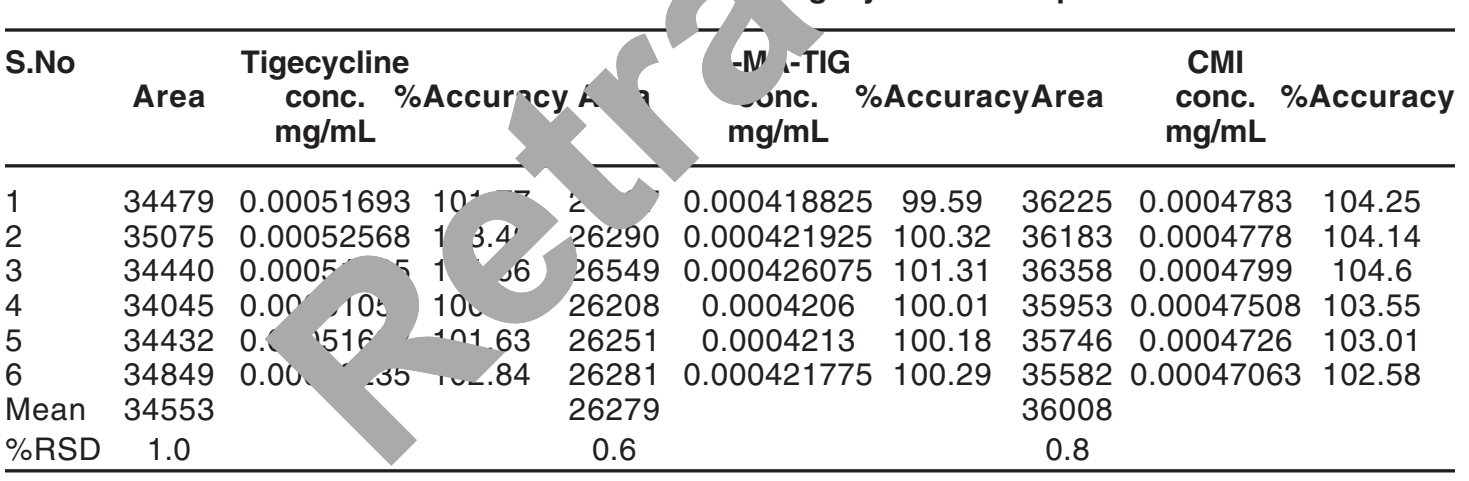

\section{Limit of Quantitation}

Asolutioncontaining $2.0317 \times 10^{-3} \mathrm{mg} / \mathrm{ml}$ of Tigecyclinestandard $(0.05 \%$ of the nominal concentrationofasample), $1.6822 \times 10^{-3} \mathrm{mg} / \mathrm{ml}$ of diMA-TIG standard $(0.04 \%$ of the nominal concentrationofasample) and $1.8352 \times 10^{-3} \mathrm{mg} /$ mlofCMI standard $(0.05 \%$ of the nominal concentrationofasample), wasinjectedsixtimes. The RSD of areas, deviation so feach six replicates from the line arregression curveandaverage deviation for each standard were calculated. Theresults of LOQ for Tigecycline and its impuritieswere presentedinTable 1.4. The limit of quantitation values obtained for each impurity and Tigecycline are within the acceptance criteria.
Table 1.5: Linearity of Tigecycline.

\begin{tabular}{lcc}
\hline$\%$ of Tigecycline & $\begin{array}{c}\text { Concentration } \\
(\mathrm{mg} / \mathrm{mL})\end{array}$ & $\begin{array}{c}\text { Average } \\
\text { Peak Area }\end{array}$ \\
\hline 0.05 & 0.00051 & 34479 \\
0.10 & 0.00102 & 67287 \\
0.15 & 0.00152 & 103231 \\
0.20 & 0.00204 & 138278 \\
0.25 & 0.00256 & 172143 \\
0.50 & 0.00512 & 348385 \\
0.70 & 0.00713 & 485950 \\
1.13 & 0.01126 & 764512 \\
\hline
\end{tabular}


Table 1.6. Linearty of di-MA-TIG.

\begin{tabular}{lcc}
\hline$\%$ di-MA-TIG & $\begin{array}{c}\text { Concentration } \\
(\mathrm{mg} / \mathrm{ml})\end{array}$ & $\begin{array}{c}\text { AveragePeak } \\
\text { Area }\end{array}$ \\
\hline 0.04 & 0.000421 & 26097 \\
0.08 & 0.000842 & 53002 \\
0.13 & 0.001263 & 78622 \\
0.17 & 0.001682 & 104520 \\
0.22 & 0.002220 & 138911 \\
\hline
\end{tabular}

Table 1.7: Linearity of CMI.

\begin{tabular}{ccc}
$\%$ of CMI Concentration $(\mathrm{mg} / \mathrm{mL})$ & $\begin{array}{c}\text { AveragePeak } \\
\text { Area }\end{array}$ \\
\hline 0.05 & 0.00046 & 36225 \\
0.09 & 0.00091 & 70502 \\
0.14 & 0.00136 & 110620 \\
0.18 & 0.00184 & 148152 \\
0.24 & 0.00238 & 197098 \\
\hline
\end{tabular}

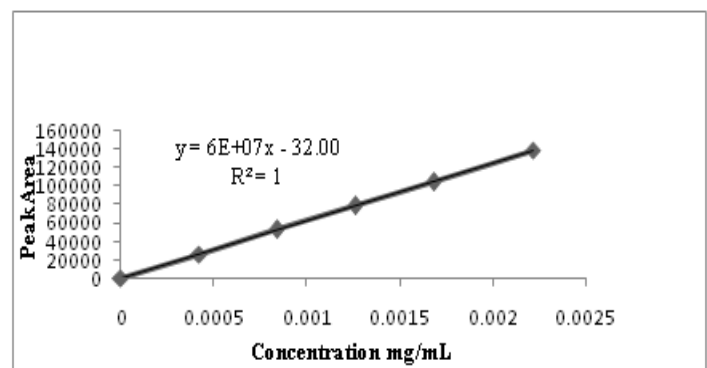

Fig 1.10. Linearity graph of CMI.

and figures 1.8-1.10 and showed the line of best fit for peak area versus concentration for each impurity. The linearity resulte for Tigecycline and all the impurities in the speci. concentration range are found satisfactory, in correlation coefficient greater than 0.99 .

\section{Accuracy}

ige lin solution spiked with a known amoun a sach impurity at five levels each in tri cute (in al 15 determinations) was prepared a ana zed as per the method.Summary of \% rec s for Tigecycline and impurities such as MA-TIG and CMI were presented in the tables $f$ om Table 1.8-1.10. The percentage recovery values obtained for each impurity are in the range of about 99.6-104.3, which are within the specified criteria. The relative standard deviation values of recoveries obtained for all impurities are in the range of $0.04 \%-0.23$.

Fig 1.8. Linearit yrap of i. sine.

ble 1.8: Summary of $\%$ recoveries for Tigecycline.

\begin{tabular}{|c|c|c|c|c|}
\hline \multicolumn{3}{|c|}{$\%$ of Tigecycline Theoretical conc. (mg/mL.) Measured conc.(mg/mL) } & \multirow{2}{*}{$\begin{array}{c}\% \text { Recovery } \\
101.77\end{array}$} & \multirow{2}{*}{$\begin{array}{c}\text { Avg. } \\
102.3\end{array}$} \\
\hline 0.05 & 0.0020317 & 0.0020677 & & \\
\hline & 0.0020317 & 0.0021027 & 103.49 & \\
\hline & 0.0020317 & 0.0020654 & 101.66 & \\
\hline \multirow[t]{3}{*}{0.10} & 0.0040714 & 0.0039961 & 98.15 & 99.0 \\
\hline & 0.0040714 & 0.0040461 & 99.38 & \\
\hline & 0.0040714 & 0.0040476 & 99.41 & \\
\hline \multirow{3}{*}{0.70} & 0.0285000 & 0.028605 & 100.37 & 100.30 \\
\hline & 0.0285000 & 0.028627 & 100.44 & \\
\hline & 0.0285000 & 0.028556 & 100.20 & \\
\hline \multirow[t]{3}{*}{1.12} & 0.0450480 & 0.044979 & 99.85 & 100.0 \\
\hline & 0.0450480 & 0.045024 & 99.95 & \\
\hline & 0.0450480 & 0.045099 & 100.11 & \\
\hline
\end{tabular}


Precision

System precision

The analysis of reference solution six times was performed and determined the percentage relative standard deviation of peak area of replicate injections of each impurity and Tigecycline. Datails of results were mentioned in the Table 1.11.

\section{Method precision}

The precision of the method is determined by analyzing a sample of Tigecycline solution spiked with impurities at $100 \%$ of the specification limit. The precision of the method for Tigecycline and its impurities were shown in the Table 1.12. The relative standard deviation observed for Tigecycline and

Table 1.9: Summary of \% recoveries for di-MA-TIG.

\begin{tabular}{|c|c|c|c|c|}
\hline$\%$ of di-MA-TIG & Theoretical conc. (mg/mL.) & Measured conc.(mg/mL) & $\%$ Recovery & Avg. \\
\hline \multirow[t]{3}{*}{0.04} & 0.0016822 & 0.0016753 & 99.59 & 100.4 \\
\hline & 0.0016822 & 0.0016877 & 100.32 & \\
\hline & 0.0016822 & 0.0017043 & 01.31 & \\
\hline \multirow[t]{3}{*}{0.12} & 0.0050516 & 0.0050387 & 74 & 99.6 \\
\hline & 0.0050516 & 0.0050062 & 3.10 & \\
\hline & 0.0050516 & 0.005056 & 00.10 & \\
\hline \multirow[t]{3}{*}{0.22} & 0.0088780 & $0.0\urcorner 889$ & 100.23 & 100.1 \\
\hline & 0.0088780 & 0.0 & 100.08 & \\
\hline & 0.0088780 & 0 & 99.89 & \\
\hline
\end{tabular}

Table 1.10: Summary af $\%$

ies for CMI

\begin{tabular}{|c|c|c|c|c|}
\hline$\%$ of CMI & Theoretical & e co $(\mathrm{mg} / \mathrm{mL})$ & \%Recovery & Avg. \\
\hline \multirow[t]{3}{*}{0.04} & 0.0018352 & 0.0019132 & 104.25 & 104.30 \\
\hline & 0.0018352 & 019112 & 104.14 & \\
\hline & 0.0018352 & 0.0019196 & 104.60 & \\
\hline \multirow[t]{3}{*}{0.13} & 0.0054521 & 0.0054682 & 100.29 & 99.60 \\
\hline & & 0.0054062 & 99.16 & \\
\hline & & 0.0054133 & 99.29 & \\
\hline \multirow[t]{3}{*}{0.23} & .537 & 0.0096005 & 100.72 & 100.70 \\
\hline & $0.0<\quad 319$ & 0.0096142 & 100.86 & \\
\hline & 0.0095319 & 0.0095904 & 100.61 & \\
\hline
\end{tabular}

Table 1.11: Summary of peak areas of the Tigecycline and its impurities.

\begin{tabular}{lccc}
\hline Injection No & Tigecycline & di-MA-TIG & CMI \\
\hline 1 & 484950 & 78622 & 110620 \\
2 & 486317 & 78114 & 109323 \\
3 & 485113 & 78903 & 109471 \\
Mean area & 485460 & 78546 & 109805 \\
\%RSD & 0.2 & 0.5 & 0.6 \\
\hline
\end{tabular}

Table 1.12: Summary of results for precision of the method.

\begin{tabular}{lcccc} 
Inj. No & $\begin{array}{c}\% \text { of di- } \\
\text { MA- } \\
\text { TIG } \\
\text { Impurity }\end{array}$ & $\begin{array}{c}\% \text { of Unknown1 } \\
\text { CMI (RRT0.86) }\end{array}$ & $\begin{array}{l}\text { Unknown2 } \\
\text { (RRT1.37) }\end{array}$ \\
\hline 1 & 0.103 & ND & 0.041 & 0.042 \\
2 & 0.105 & ND & 0.044 & 0.042 \\
3 & 0.105 & ND & 0.042 & 0.042 \\
4 & 0.103 & ND & 0.044 & 0.042 \\
5 & 0.103 & ND & 0.042 & 0.042 \\
6 & 0.103 & ND & 0.046 & 0.041 \\
Mean (\%) & 0.10 & N/A & 0.04 & 0.04 \\
$\%$ RSD & 0.09 & N/A & 0.0 & 0.0 \\
\hline
\end{tabular}


impurities are less than $10 \%$. The results comply with the acceptance criteria and indicate acceptable precision of the system.

\section{RESULTS AND DISCUSSION}

A simple, economic, accurate and precise HPLC method was successfully developed by using Zorbax Eclipse plus C18 $(100 \mathrm{~mm} \times 4.6 \mathrm{~mm}, 1.8$ $\mu \mathrm{m}$ particlesize). Injection volume of $10 \mu \mathrm{l}$ is injected and eluted with the mobile phase eluent-A: $\mathrm{pH} 6.50$ buffer: acetonitrile: DMSO (90:5:5 \%v/v/v) and eluent-B: pH 6.50 buffer: acetonitrile: DMSO (71:24:5 $\% \mathrm{v} / \mathrm{v} / \mathrm{v})$, which is pumped at a flow rate of $1.0 \mathrm{ml} /$ $\mathrm{min}$. Detection, was carried out at $270 \mathrm{~nm}$. The results obtained were accurate and reproducible.The method developed was statistically validated in terms of Selectivity, accuracy, linearity, precision, robustness, and stability of solution.

For Selectivity, the chromatograms were recorded for standard and sample solutions of Tigecycline and its related substances. Selectivit studies reveal that the peak is well separated fr, each other. Therefore the method is select $e$ for the determination of related su $\mathrm{s}^{\mathrm{t}} \mathrm{m}$, in Tigecycline. The limit of detection (LO nd lir of quantitation (LOQ) for di-MA-TIG imnurı, 001 and $0.0004 \mathrm{mg} / \mathrm{ml}$, CMI imp ity .0001 and $0.0004 \mu \mathrm{g} / \mathrm{ml}$, Tigecyclir 00 id $000 \mathrm{mg} /$ $\mathrm{ml}$ respectively Usir tho optimized chromatographic co ic ention times of impurities were 13.50 fo "MA-TIG impurity, 16.75 for $\mathrm{CMI}$, and 14.35 for $\mathrm{T}$ - cycline. The linearity results for Tigecycline and all the impurities in the specified concentration range are found satisfactory, with a correlation coefficient greater than 0.99.Calibration curve was plotted and correlation co-efficient for Tigecycline and its impurities found to be $1.000,1.000$, and 0.9999 respectively.

The accuracy studies were shown as \% recovery for Tigecycline and its impurities at specification level. The limit of \% recovered shown is in the range of 90 and $110 \%$ and the results obtained were found to be within the limits. Hence the method was found to be accurate. The accuracy studies showed \% recovery of the Tigecycline and its related substances in the range 99.6 to104.30 respectively.For Precision studies six replicate injections were perfo ed. \% RSD was determined from the peak areas of cycline and its impurities. The acceptance lim sho be not more than 10, and the results $n$ fo ind to be within the acceptance I

\section{NCLUSIONS}

A smiple and precise RP-HPLC method $h$ beer eveloped by the author for the estimation of ro._a impurities present in the Tigecycline and 1. as observed that the chromatographic method eveloped for Tigecycline and its related substances are rapid, sensitive, precise, and accurate. Therefore, the proposed method can be successfully applied for the routine analysis of the active pharmaceutical ingredients for assurance of its quality during its formulation.

\section{ACKNOWLEDGEMENTS}

The author was thankful to the Head, Department of Chemistry and the authorities of Gitam University, Vishakhapatnam for providing necessary scientific support and help.

\section{REFERENCES}

1. Lucelia, M.S.;Herida,R.N.S.Tigecycline: A review of properties application and analytical methods, Ther. drug monitoring, 2010, 32(3),282-287.

2. Aparna,B.C.;Dipti,B.P.AUC spectrophotometric method for the determination of Tigecycline in pharmaceutical formulations, J. of Pharm. Sci. and Bio scientific Res., 2012,2(2), 88-91.

3. Silva, L.M.; Salgado, H.R.N.Development and validation of spectrophotometric method for the assay of Tigecycline in lyophilized powder, International congress of Pharmaceutical sciences, CIFARP-2011, 2011.

4. Lucelia,M.S.;Adelia,E.A.;Herida,R.N.S. 
Thermal analysis and validation of UV spectrophotometric methods for the determination of new antibiotic Tigecycline in pharmaceutical products, $A d v$. in analytical.chem, 2012, 2(1), 10-15.

5. Srikanth,K.;Reddy,D.R.;Venkatesan,C.S. Development and validation of RP-HPLC pre-column derivatisation for the trace level determinatrion of ter-butyl amine in Tigecycline drug substance, Int. j. of pharm. and Biological sci, 2013,4(2), 522-531.

6. Chonghuva, L.;Christina, A.S. Quantification of Tigecycline: A novel glycylcycline by liquid chromatography,J. chromatography. B, 2004, 811,225-229.

7. Allena, J.J.; James, P.S.A sensitive human bone assay for the quatification of Tigecycline using LC/MS/MS,J. of Pharm. and
Biomed.Anal, 2008,48,866-875.

8. Patel, D.; Parikh, K.S. Stability indicating RPHPLC method development and its validation for the quatification of Tigecycline in lyophilized parental preparation, Int. j.Chemtech Applications, 2013,2(1), 77-86.

9. $\mathrm{ICH}$ Guidance on analytical method validation, international convention on quality for the pharmaceutical industry, Toronto, Canada, 2002.

10. ICH Q1B IFPMA, Stability testing: photostability testing of new drug substances and products, International Conference on Harmonizatior Geneva, Switzerland, 1996.

11. $\mathrm{ICH}$ of technt requirements for the registration o ,har, eutical for the human use, validatio if an Iytical procedures: text and $m$ a $\log _{y}, \ldots \mathrm{H}, \mathrm{Q} 2$ (R1), 2005. 